\title{
Impact of a randomized school-based intervention program on blood pressure levels
}

Raiani Spalenza Matos 1

Dhttps://orcid.org/0000-0003-2501-4997

Jordana Herzog Siqueira 2

(iD) https://orcid.org/0000-0003-0116-7411

Diana Barbosa Cunha 3

https://orcid.org/0000-0003-0900-5628

Maria del Carmen Bisi Molina 4

http://orcid.org/0000-0002-8614-988X

1 Programa de Pós-Graduação em Nutrição e Saúde. Universidade Federal do Espírito Santo. Vitória, ES, Brasil.

2,4 Programa de Pós-Graduação em Saúde Coletiva. Universidade Federal do Espírito Santo. Av. Marechal Campos, 1468. Maruípe. Vitória, ES, Brasil. CEP: 29.040-090. E-mail: mdcarmen2007@gmail.com

3 Instituto de Medicina Social. Universidade do Estado do Rio de Janeiro. Rio de Janeiro, RJ, Brasil.

\begin{abstract}
Objectives: to evaluate the impact of a health program performed in a school setting on the blood pressure levels of schoolchildren in the public school system in Vitória/ES-Brazil.

Methods: a randomized community trial was performed with 237 schoolchildren (6 to 12 years) from two public schools, randomly defined as the intervention and control school. Participants of the intervention group attended 11 education sessions over 4 months (July to October 2014). To test for differences between groups, the chi-square (categorical variables), and the paired t test or Wilcoxon (continuous variables) was used. The rate of variation of systolic blood pressure (SBP) and diastolic blood pressure (DBP) throughout the follow-up, according to allocation group, was evaluated using linear generalized models for timerepeated measures.

Results: there was a reduction in the means of $S B P(0.5 \mathrm{mmHg})$ and $D B P(0.6 \mathrm{mmHg})$ in the intervention group and an increase in the control group, with a significant difference in the BP variation between groups over the follow-up period $(p<0.05)$.

Conclusion: a low-cost and easily implemented intervention may be one of the factors associated with the lowest blood pressure levels in the group studied, and reproduction in a school environment is feasible.

Key words Clinical trial, Arterial pressure, Child, Adolescent
\end{abstract}

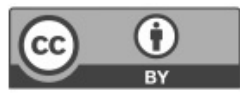




\section{Introduction}

Noncommunicable diseases (NCDs) are the leading cause of death globally, and one of the major health challenges of the $21^{\text {st }}$ century. Particularly, cardiovascular diseases are currently the leading cause of death and one of the greatest health challenges worldwide. In 2016, NCDs were responsible for $71 \%$ (41 million) of the 57 million deaths that occurred worldwide, of which $44 \%$ were due to cardiovascular diseases. ${ }^{1}$

One of the most important risk factors for cardiovascular diseases is hypertension. ${ }^{2}$ The usual pressure level above $115 / 75 \mathrm{mmHg}$ is associated with a progressive, linear, continuous and independent increase in mortality from these diseases. ${ }^{3}$ Several risk factors are involved in the development of hypertension, including behavioural factors, such as the high consumption of foods rich in salt and fat, low consumption of fruits and vegetables, and physical inactivity, which are highly influenced by the conditions of peoples' lives. 4

Although the prevalence of high blood pressure (BP) is lower among children and adolescents compared to adults, there is evidence that essential hypertension begins to develop during the first two decades of life, when pressure levels rise steadily. ${ }^{5} \mathrm{~A}$ study performed with a representative sample of Brazilian adolescents showed the prevalence of hypertension was 9.6\%.6 According to a metaanalysis, BP in childhood is associated with BP in adulthood, so BP monitoring is important since childhood to perform early interventions. 7 In this context, school is a propitious place for conducting health programs when students are in the learning phase and is appropriate for the formation of attitudes, values, and behaviours in addition to being a suitable place for the formation of critical thinking and autonomy for the development of healthy practices. ${ }^{8}$

It is already known that hypertension in children is underreported and undertreated. In addition, although few intervention studies have been done, most have occurred in high-income countries and the best performance was seen when diet was combined with the practice of physical activity. 9

Considering the scarcity of intervention studies involving healthy eating and physical activity with Brazilian children, the objective of this study is to evaluate the impact of a health program conducted in a school setting on the blood pressure levels of schoolchildren in the public school system in Vitória/ES-Brazil.

\section{Methods}

The present study is part of an intervention study conducted at Municipal Schools of Primary Education in Vitória, Espírito Santo, Brazil. The Health Center Region, chosen for this study, includes five schools in the municipal education network, totalling 450 students. Of these five schools, two were selected and randomly assigned as either the "intervention" or "control" school. All schoolchildren of both sexes enrolled in second to fifth grade classes at these two schools were invited to participate in the study.

All eligible participants needed an informed consent form signed by the parents/guardians, and an assent term signed by the child. The exclusion criteria were any physical or mental impairment of the student that would make data collection or performing the activities impossible. The study was conducted and reported according to the CONSORT guideline for cluster-randomized trials. 10

The final sample consisted of 237 students, of whom 149 were from the intervention school, and 88 were from the control school. This sample size has a power of $50 \%$ and a significance level of $10 \%$ to detect a difference in DBP level of $1.5 \mathrm{mmHg}$. A reduction of $0.5 \mathrm{mmHg}$ was observed by Angelopoulos et al.11 in adolescents after a schoolbased intervention program.

Anthropometric and haemodynamic data were collected from the schoolchildren by trained project researchers in the school environment. A structured questionnaire containing questions related to the socioeconomic status, eating habits and physical activity practices of the student was sent home to be filled out by the parents/guardians of the students. The data were collected at two time points in the two schools (intervention and control), before and after the educational actions. The first data collection was in March 2014, and the last was in late October of the same year. For the collection of anthropometric data, the children wore a school uniform (light clothing), without shoes and accessories.

To measure the weight, a Tanita ${ }^{\circledR}$ (BF-680W) digital scale was used, with precision of $100 \mathrm{~g}$ and capacity of $150 \mathrm{~kg}$. Height was measured using a Cardiomed ${ }^{\circledR}$ stadiometer with an accuracy of $1 \mathrm{~mm}$ and amplitude of $200 \mathrm{~cm}$. Both measurements were taken with the pupil erect, with arms extended along the body, looking at the Frankfurt plane, barefoot, and wearing school uniforms. The BMI for age was calculated using the WHO AnthroPlus ${ }^{\circledR}$ software.

To measure arm circumference, a Sanny ${ }^{\circledR}$ (TR4010) inextensible tape measure was used. It was 
positioned around the arm, at the midpoint between the acromion and the olecranon according to the technique recommended by Cameron (1984). ${ }^{12}$

The outcome of this paper is blood pressure variation. The BP measurement was performed according to the methodology established by the VI Brazilian Guidelines for Hypertension, 13 using the Omron ${ }^{\circledR}$ (HEM-705CPINT) digital device. It was calibrated, and the cuffs were appropriate for the circumference of the left arm of each individual, with an infant size for an arm circumference of 16 to $22 \mathrm{~cm}$, and an adult size of 23 to $33 \mathrm{~cm}$. BP was measured at the school in a calm environment after 5 minutes of rest, and three measurements were taken with an interval of approximately two minutes, assuming a difference of up to $5 \mathrm{mmHg}$ between measurements. For a difference greater than 5 $\mathrm{mmHg}$, three more measurements were taken. For haemodynamic evaluation, all children had an empty stomach and were without physical activity for at least 60 minutes. During the examination, the student remained seated with legs uncrossed, feet resting on the floor, back resting on the chair and relaxed, with arm raised at the height of the heart and free of clothes, with palms facing upwards and slightly flexed elbows. Participants were also instructed not to speak during the measurements, and before starting the first measurement, the entire procedure was explained to the students to reduce the alarm reaction. BP was measured in the morning shift and the protocol was the same in the two schools evaluated.

For the analyses, the first measurement was discarded and the average of the other two valid measurements was used. Data were analysed considering age, sex, and height percentile according to the V Brazilian Guidelines for Hypertension. ${ }^{14}$ The systolic blood pressure (SBP) and diastolic blood pressure (DBP) of the schoolchildren was classified as follows: normal, $<90^{\text {th }}$ percentile; borderline, from percentile $\geq 90$ to $<95$ or if $\mathrm{BP} \geq 120 / 80 \mathrm{mmHg}$, and elevated, $\geq 95^{\text {th }}$ percentile, in order to describe the studied sample.

Food consumption was measured using a food frequency questionnaire, answered by the parents/guardians of the students. To evaluate food quality, the School Child Diet Index (SCD) was used, as proposed by Molina et al., 15 which is based on the frequency of consumption of 15 food items and the practice of eating breakfast. The SCD index provides a positive or negative score for each specific frequency of consumption and, after the individual sum of scores, classifies the student's diet into three categories: $\leq 3$ was low quality, between
$>3$ and $<6$ was intermediate quality, and $\geq 6$ was good quality. 15

Physical activity and screen time among the schoolchildren were measured using a questionnaire validated by Fernandes et al. 16 for children. Screen time was evaluated according to the sum of the daily time spent with screen devices (television, video game, and computer). A cut-off point of 120 minutes/day was used, which is the maximum time recommended by the American Academy of Pediatrics. ${ }^{17}$ The practice of physical activity was quantified according to the sum of supervised physical activity time, active play, and active shift from home to school and from school to home. For this variable, a cut-off point of 300 minutes/week was used, considering a minimum value of 60 minutes daily recommended for children. 18

The race of the schoolchildren was classified by two interviewers of the project, and in case of divergence in the classifications, a third researcher was asked to evaluate. Skin color, hair shape, and facial characteristics were taken into account to classify the individuals as white, black, or brown (pardo).

The classification of socioeconomic conditions was based on information provided by the questionnaire sent to the household according to the criteria of the Brazilian Association of Research Companies (2012). 19

The intervention group went through educational actions that occurred in the school, during class hours, lasting 50 minutes and in the presence of a teacher. The methodology used was that of group workshops, with active participation of the students.

A total of eleven meetings were held every two weeks from July to October 2014 (Table 1). We reiterate that the children at the two schools (intervention and control) were the same to allow comparison of the results.

The workshops were developed and carried out by researchers of the project, including undergraduate students, nutritionists, and physical educators. The proposed themes were based on promoting healthy eating habits and encouraging physical activity. This was based on Brazilian publication related to healthy food and food education and nutrition, such as the Food and Nutrition Education Reference Framework for Public Policies.20 The educational methodologies varied among the age groups, respecting the autonomy of those involved to make decisions for their health and collective incorporation of the topics addressed. For the youngest we adapted the actions in a playful way. Educational reading material was also sent from school to home for review by the family of the chil- 
Table 1

Intervention components, objectives, and methodology of the education actions.

Intervention components $\quad$ Objectives $\quad$ Methodology

1) Food preferences and relation with nutrition

2) Identification of points of sale of food near the school and the children's homes

3) Diversity of fruits and vegetables and the benefits of five colors (red, orange, green, purple, and white)

4) Food labeling and TV advertising

5) Active play

6) Reviewing the benefits of the five colors of fruits and vegetables

7) Fruit tasting

8) Assessment of the interventions

9) Identification of colleagues for playing and physical activities

10) Identification of places for physical activity

11) Education actions review
To know the schoolchildren's eating habits and understand the nutrition process

To know points of sale in the children's and the school's neighborhood

To present and show the importance by means of interactive games - of the benefits of colorful foods

To excite curiosity about reading labels and warn about food ads, as well as develop critical thinking

To encourage the practice of physical activities and show that not much room or resources are needed to exercise

To re-emphasize the benefits of regula consumption of fruits and vegetables through an analysis of their nutrients based on the food's colors

To show the diversity of fruits and encourage regular eating

To observe the changes/ effects of the workshops

To collect reports of affection and engaging in physical activity outside the school

To know the places near the children's homes which were identified as potential places for playing

To recall and assimilate the education actions review contents
Recording with words or drawings the foods they like, do not like, and are good for health

Observation of the school and the children's residence neighborhood, and recording what was observed

Dynamic games with riddles relating to fruits and vegetables

Reading food labels and showing advertisements as well as test tubes with amounts of salt, sugar and fat as contained in the food consumed by children

Series of playing (hopscotch, elastic, running with balloons) and recalling of parents' games during the chat groups

Dynamic game of filling in posters with the names of fruits and vegetables with each of the five colors

Blind tasting and guess dynamics in which the children tasted fruits that they usually eat and other exotic fruits

Recording, with words or drawings, the food preferences, the changes after the workshops, and the foods they intend to try

Division of groups for running activities and questions about affection

Division of groups for tracing the places available for playing and physical activities close to their homes

Chat panels and delivery of educational materia to be read with the family dren and adolescents. After each educational action, the students showed their satisfaction using a hedonic scale.

Two lectures on diet were given to the participants in the control group, during 2014, lasting one hour each. The objective of these meetings was to maintain the link with the school and with the participants of the research, using traditional expositive methodology.

To describe the study variables, measures of central tendency and dispersion for continuous vari- ables and percentages for categorical variables were used. The Kolmogorov Smirnov test was used to test the normality of variables, and the statistics were calculated according to this result. For analysis of the differences of proportions in qualitative variables, the chi-square test was used. For the continuous variables, the $t$-test and Wilcoxon's test were used to check for differences in paired samples. The statistical significance level used was $p \leq 0.05$ and the analyses were carried out using the SPSS statistical software, version 23.0.The rate of variation of the 
systolic and diastolic blood pressure of the students during the follow-up, according to allocation group (intervention or control), was evaluated through linear generalized models for time-repeated measures, using the PROC MIXED procedure in SAS version 9.4 (SAS Institute, Inc.) statistical software. The main effect of the nutritional intervention program was determined by the interaction term allocation group $\mathrm{x}$ time. The appropriate covariance structure was tested for each analysis. The value of $p \leq 0.05$ was adopted as significant.

The present study was approved by the Research Ethics Committee of the Federal University of Espírito Santo under protocol no. 242,848, registered in the World Health Organization under UTNU111111553103 and registered in the Brazilian Registry of Clinical Trials (Identifier RBR-4j9fxq).

Participation in the research was voluntary and was confirmed by signing the informed consent form by those responsible, and the assent term was signed by the schoolchildren.

The children identified with high BP were referred for medical evaluation by project collaborators belonging to the municipal health service, and at the end of the program (September), all students in the control group went through the workshops performed in the intervention group, thus providing the same benefits to both groups.

\section{Results}

There were no sample losses during the follow-up (Figure 1). There was no difference between groups, for sex, age, school year, nutritional status, blood pressure, quality of diet, physical activity level, and screen time at baseline. A significant difference was observed in race $(41.6 \%$ of the intervention group and $15.9 \%$ of the control school students were white) $(p<0.001)$ and in socioeconomic class $(p<0.001)$ (Table 2).

Mean values before and after the educational actions are found in Table 3. There was a significant increase in the means of weight, height, and BMI in both schools after the intervention $(p<0.001)$. There was a reduction in mean $\mathrm{SBP}(0.5 \mathrm{mmHg})$ and DBP $(0.6 \mathrm{mmHg})$ in the intervention group, and a significant increase of $1.8 \mathrm{mmHg}$ in SBP and $2.2 \mathrm{mmHg}$ in DBP in the control group. There was a significant reduction in screen time among intervention school participants, a significant increase in both physical activity level and SCD index in the control school.

The rate of variation of blood pressure over time was different between students of the intervention and control schools, both for SBP $(p=0.022)$ and
DBP $(p=0.001)$, with a decrease in the means of SBP and DBP among participants in the intervention group and an increase in means during follow-up in the control group (Figure 2).

\section{Discussion}

In the present study, a school-based intervention may be one of the factors associated with the lowest blood pressure levels in the group studied. It was observed that the proposal was effective, indicating the importance of interventions based on the promotion of healthy eating habits and the incentive to engage in physical activity in the school environment.

Angeloupolos et al.,11 in a study conducted with fifth-year schoolchildren in the city of Loannina, Greece, carried out an intervention focused on overcoming the barriers in accessing physical activity areas, increasing the availability of fruits and vegetables, and increasing parental support. In this study, an increase was observed in SBP and DBP in the control group, and a reduction in the intervention group. These authors attributed the favourable effects on the BP of the intervention group to the reduction of BMI, different from our study because there was an increase in BMI in the two groups studied. However, similar to another study, in both schools, there was an increase in the means of weight, height, and BMI when the two evaluation time points were compared.21 The increase in anthropometric indices was expected because the students are in a growth and development phase. In addition, the intervention program was short-lived, and changes in nutritional status may need a longer period of time to achieve benefits. Therefore, the reduction of pressure observed in our study did not occur through reduction of BMI.

Two recent clinical trials published in developed countries, one with Spanish adolescents, 21 and the other with obese children in the United States, 22 both evaluated the impact of an intervention based on a physical activity program focusing on promoting a healthy lifestyle. In both studies, an improvement in cardiovascular health was observed in the intervention group, such as a decrease in blood pressure levels.

An important aspect observed was the high screen time among most schoolchildren, similar to that found in the National School Health Survey (PeNSE - Portuguese acronym), in which approximately $60 \%$ of the sample reported watching more than 2 hours of television during a single day of the week. When asked about the time spent sitting not 


\section{Figure 1}

Flowchart of the study.

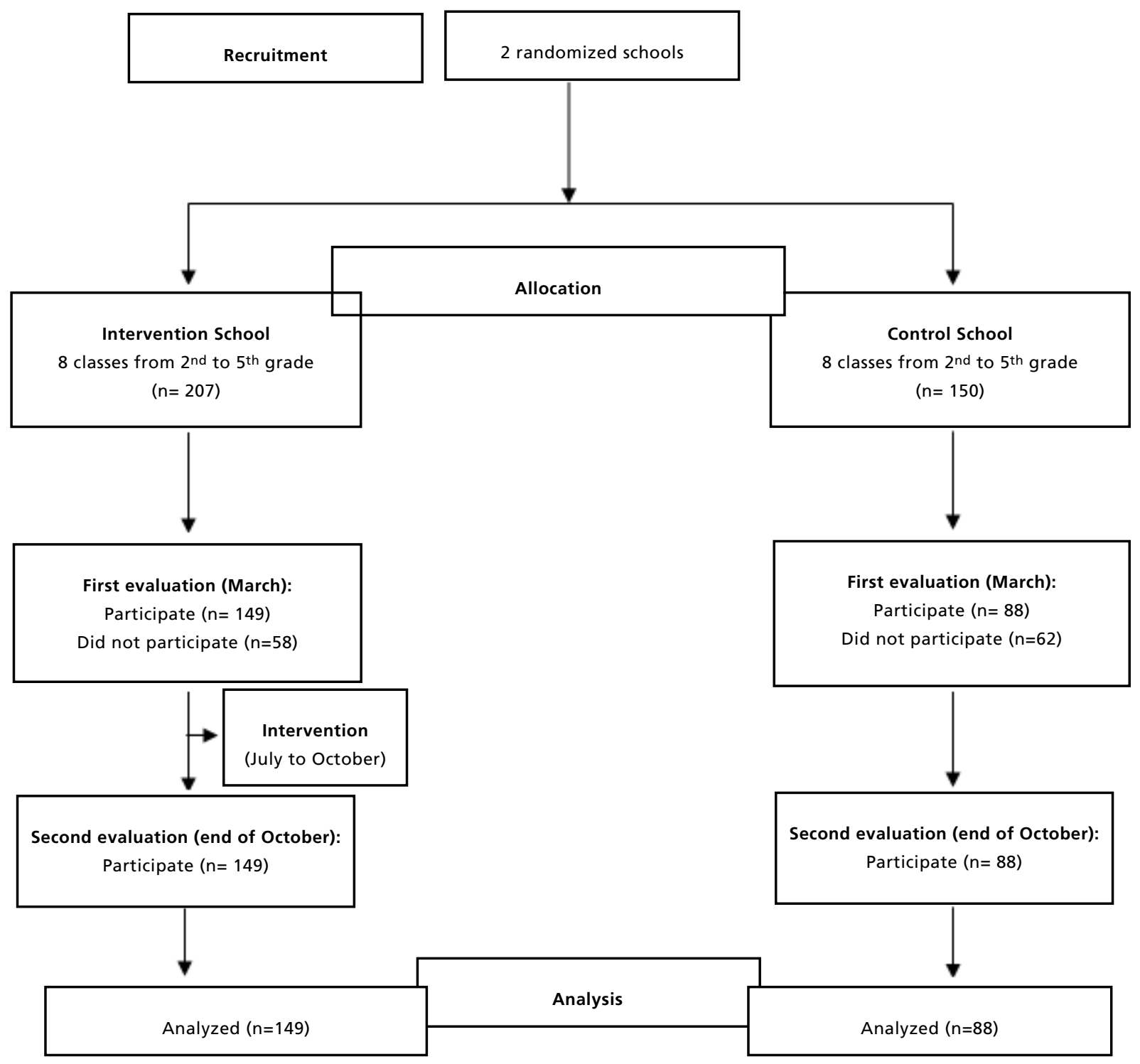


Table 2

\begin{tabular}{|c|c|c|c|c|c|}
\hline \multirow[t]{2}{*}{ Variables } & \multicolumn{2}{|c|}{ Intervention School } & \multicolumn{2}{|c|}{ Control School } & \multirow[t]{2}{*}{$p$} \\
\hline & $\mathrm{n}$ & $\%$ & $\mathrm{n}$ & $\%$ & \\
\hline Sex & & & & & 0.862 \\
\hline Male & 66 & 44.3 & 40 & 45.5 & \\
\hline Female & 83 & 55.7 & 48 & 54.5 & \\
\hline Age (years) & & & & & 0.342 \\
\hline 6 and 7 & 39 & 26.2 & 24 & 27.3 & \\
\hline 8 and 9 & 58 & 38.9 & 41 & 46.6 & \\
\hline$\geq 10$ & 52 & 34.9 & 23 & 26.1 & \\
\hline Race/Ethnicity & & & & & $<0.001$ \\
\hline White & 62 & 41.6 & 14 & 15.9 & \\
\hline Black & 41 & 27.5 & 32 & 36.4 & \\
\hline Brown & 46 & 30.9 & 42 & 47.7 & \\
\hline Socioeconomic class** & & & & & $<0.001$ \\
\hline$A$ and $B$ & 66 & 44.3 & 13 & 14.9 & \\
\hline c & 67 & 45.0 & 64 & 73.6 & \\
\hline $\mathrm{D}$ and $\mathrm{E}$ & 16 & 10.7 & 10 & 11.5 & \\
\hline School year & & & & & 0.561 \\
\hline $2^{\text {nd }}$ & 36 & 24.2 & 23 & 26.1 & \\
\hline $3 \mathrm{rd}$ & 36 & 24.2 & 22 & 25.0 & \\
\hline $4^{\text {th }}$ & 26 & 17.4 & 20 & 22.7 & \\
\hline $5^{\text {th }}$ & 51 & 34.2 & 23 & 26.1 & \\
\hline Blood pressure & & & & & $0.445 *$ \\
\hline Normal & 144 & 96.6 & 84 & 95.5 & \\
\hline Borderline and Elevated & 5 & 3.4 & 4 & 4.5 & \\
\hline Food quality** & & & & & 0.110 \\
\hline Low quality & 42 & 28.2 & 36 & 41.4 & \\
\hline Intermediate quality & 37 & 24.8 & 19 & 21.8 & \\
\hline Good quality & 70 & 47.0 & 32 & 36.8 & \\
\hline Physical activity** & & & & & 0.701 \\
\hline$\geq 300$ minutes/week & 129 & 86.6 & 73 & 83.9 & \\
\hline$<300$ minutes/week & 20 & 13.4 & 14 & 16.1 & \\
\hline Screen time** & & & & & 0.857 \\
\hline$\leq 120$ minutes/day & 24 & 16.1 & 15 & 17.2 & \\
\hline$>120$ minutes/day & 125 & 83.9 & 72 & 82.8 & \\
\hline BMI/Age $\left(\mathrm{kg} / \mathrm{m}^{2}\right)$ & 18.6 & 3.8 & 17.5 & 3.3 & 0.065 \\
\hline
\end{tabular}

Data were expressed as $\mathrm{n}(\%)$ for categorical variables and mean \pm SD for continuous variables.

Chi-square test. * Wilcoxon Test; ** One child from the control school did not have data for food quality, socioeconomic class, physical activity, or screen time; $\mathrm{BMI}=$ Body Mass Index.

only watching television but also using other screen devices, such as computers and video games, more than $50 \%$ of students reported more than 3 hours of sitting. ${ }^{23}$ In our study, we observed a significant reduction in screen time among students in the intervention group, a result already reported in another study of our research group, which evaluated students in the 7 to 10 age group. 24 This reduction in screen time contributed to a reduction, although not significant, in blood pressure levels in this group; the control group presented a significant increase in the practice of physical activity, but there was no impact on blood pressure. Both high screen time and physical inactivity are associated with deleterious health effects, and although an individual may be physically active, physical activity may not compensate for the adverse effects of prolonged exposure to a sedentary lifestyle. 25 


\section{Table 3}

Anthropometric, haemodynamic, physical activity, screen time, and food quality variables according to allocation group, before and after interventions.

\begin{tabular}{|c|c|c|c|c|c|c|}
\hline & \multicolumn{2}{|c|}{ Intervention School } & \multirow[t]{3}{*}{$p$} & \multicolumn{2}{|c|}{ Control School } & \multirow[t]{3}{*}{$p$} \\
\hline & Initial Evaluation & Final Evaluation & & Initial Evaluation & Final Evaluation & \\
\hline & $\bar{X} \pm S D($ Median $)$ & $\bar{X} \pm S D($ Median) & & $\overline{\mathrm{X}} \pm \mathrm{SD}$ (Median) & $\bar{X} \pm S D$ (Median) & \\
\hline Weight (kg) & $35.7 \pm 11.5(33.2)$ & $38.3 \pm 12.5(35.6)$ & $<0.001 *$ & $32.2 \pm 9.6(29.7)$ & $34.4 \pm 10.4(31.1)$ & $<0.001 *$ \\
\hline Height(cm) & $137 \pm 11(137)$ & $140 \pm 12(139)$ & $<0.001$ & $135 \pm 10(135)$ & $138 \pm 10(137)$ & $<0.001$ \\
\hline BMI/Age $\left(\mathrm{kg} / \mathrm{m}^{2}\right)$ & $18.6 \pm 3.8(17.4)$ & $19.1 \pm 4(17.9)$ & $<0.001 *$ & $17.5 \pm 3.3(16.3)$ & $17.8 \pm 3.4(16.8)$ & $<0.001$ * \\
\hline SBP $(\mathrm{mmHg})$ & $99.4 \pm 8.3(99)$ & $98.9 \pm 7.8(99)$ & 0.345 & $100.6 \pm 7.0(100)$ & $102.4 \pm 7.1(102)$ & 0.052 \\
\hline $\mathrm{DBP}(\mathrm{mmHg})$ & $60.5 \pm 7.3(60)$ & $59.9 \pm 5.6(60)$ & $0.320 *$ & $60.3 \pm 6.2(59.5)$ & $62.5 \pm 6.1(62)$ & $0.002 *$ \\
\hline Screen time $(\min /$ day $) * *$ & $295 \pm 154(300)$ & $261 \pm 152(240)$ & $0.010 *$ & $284 \pm 155(270)$ & $263 \pm 150(270)$ & 0.083 \\
\hline Physical activity (min/week)** & $1.076 \pm 699(950)$ & $1.159 \pm 756(990)$ & $0.129 *$ & $1.120 \pm 717(1.010)$ & $1.235 \pm 819(1.130)$ & 0.034 \\
\hline SCD index** & $5.3 \pm 3.6(5)$ & $5.4 \pm 3.5(5)$ & 0.377 * & $4.4 \pm 3.2(4)$ & $5.4 \pm 3.29(5)$ & $0.001 *$ \\
\hline
\end{tabular}

Data are presented as the mean \pm standard deviation (and median); Paired t-test; *Wilcoxon test; $\mathrm{BMI}=\mathrm{Body} \mathrm{Mass}$ Index; $\mathrm{SBP}=\mathrm{Systolic}$ blood pressure; $\mathrm{DBP}=$ Diastolic blood pressure; ** The data for one child from control school do not include food quality, socioeconomic class, physical activity, or screen time; $\mathrm{SCD}=$ School Child Diet Index.

Figure 2

Variation of the modelled means of blood pressure over time, for the intervention and control groups.
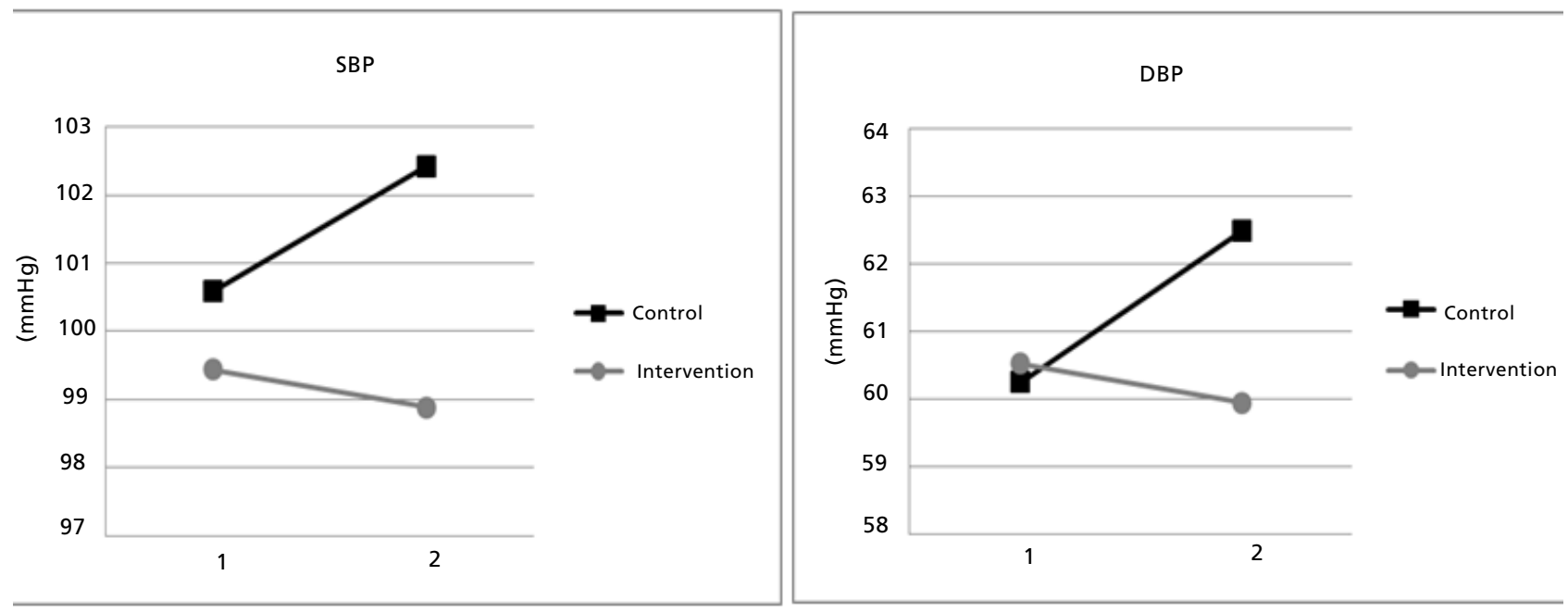

$\mathrm{SBP}=$ Systolic blood pressure; $\mathrm{DBP}=$ Diastolic blood pressure; 1: Initial evaluation; 2: Final evaluation

Generalized linear model adjusted for socioeconomic status; Time by Intervention/Control for SBP (0.022) and DBP (0.001). 
There was a difference in race and socioeconomic class between intervention and control groups at baseline. We chose to adjust the model by socioeconomic class because there were no relevant pressure differences between ethnic groups during childhood 26 ; however, the results remained even after adjustment.

The means of the diet quality index between the groups at both evaluation times were lower than 6 , lower values than found in Momm and Hofelmann. 27

They used the same index with schoolchildren from 6 to 11 years in Santa Catarina, and the average was 6.97 points. Notably, there was a significant increase in the mean of the SCD index in the contro school when the two time points were compared, but it remained below that of the intervention school, and there was no significant difference between the two schools at the second evaluation point (data not shown).

Eating behaviour during childhood is strongly influenced by parents, and thus, interventions to modify eating habits of children should involve their relatives. 28 In our study, the parents/guardians of the students were invited to participate in events held at the school outside of school hours, but the families' adherence to the program was low. Oosterhoff et al.,29 in a systematic review and meta-analysis to assess the impact of school-based lifestyle interventions on BMI and children's blood pressure, found that parental involvement accentuated the beneficial effects of interventions.

Some limitations were found in the study, such as the teachers' strike in early 2014 , which partially modified the intervention schedule. This situation was minimized shortly after the fast return of activities. Among the strengths of our study is the satisfaction of the great majority of schoolchildren, shown through the hedonic scale after the interventions, the consistent participation throughout the follow-up period - with no sample loss during the study - and the construction and execution of workshops by several health professionals, providing the exchange of knowledge. It is important to mention that in Brazil, although food frequency questionnaires (FFQs) were developed and validated, the present SCD index to evaluate the child diet quality was a pioneer in the literature. If, on the one hand, the use of a summarized FFQ shows advantages over extended versions, on the other hand it may lead to an underestimation of the consumption of some foods, since it is necessary to group several foods of frequent consumption under a single item. In the case of children, this option may represent an advan- tage, considering the possible protocol to be followed with children in the age group studied. Another limitation is the use of an index that only aims to inform the frequency of food items, not allowing quantification of portions of food or groups of food consumed over a given period. Even with the limitations of the index used to assess the child diet quality, these are not a limitation of the study, since food consumption data, although possibly not highly accurate, was used to compare data from intervention and control groups. In this way, the possible error is evenly distributed between the groups.

In conclusion, the proposed intervention may be one of the factors associated with the lowest blood pressure levels in the group studied, and reproduction in a school environment is feasible. It should be emphasized that intervention programs similar to those developed in this study may aid in the development of public policies for the control and reduction of chronic diseases in the population of children and adolescents.

\section{Acknowledgments}

We thank FAPES (Fundação de Amparo à Pesquisa $e$ Inovação do Espirito Santo) for the financial support for the research in Espírito Santo, Brazil (grant $n^{\circ}$. 60927089/13).

\section{Authors' contribution}

Matos RS performed the analysis and interpretation of data and the writing of the article. Siqueira $\mathrm{JH}$ performed the data collection and critical review of content. Cunha DB assisted in data analysis and critical review of content. Molina MCB assisted in the design of the study, data acquisition, critical review of content and final approval of its version for publication. 


\section{References}

1. Global Health Estimates 2016: Deaths by Cause, Age, Sex, by Country and by Region, 2000-2016. Geneva: World Health Organization; 2018.

2. WHO (World Health Organization). Global Atlas on Cardiovascular Disease Prevention and Control. Geneva; 2011.

3. Lewington S, Clarke R, Qizilbash N, Peto R, Collins R, Prospective Studies Collaboration. Age-specific relevance of usual blood pressure to vascular mortality: a metaanalysis of individual data for one million adults in 61 prospective studies. Lancet. 2002; 360 (9349):1903-13.

4. WHO (World Health Organization). A Global Brief on Hypertension: Silent Killer, Global Public Health Crisis. Geneva; 2013.

5. Sinaiko AR. Hypertension in Children. New Engl J Med 1996; 335: 1968-73.

6. Bloch KV, Klein CH, Szklo M, Kuschnir MCC, AbreuGA, Barufaldi LA, Veiga GV, Schaan B, Silva TLN and other authors. ERICA: prevalences of hypertension and obesity in Brazilian adolescents. Rev Saúde Pública. 2016; 50: 9s.

7. Chen X, Wang Y. Tracking of blood pressure from childhood to adulthood: a systematic review and meta-regression analysis. Circulation. 2008; 117: 3171-80.

8. Brasil. Ministério da Saúde. Organização Pan-Americana de Saúde. Escolas promotoras de saúde: experiências no Brasil. Brasília, DF; 2007.

9. Cai L, Wu Y, Wilson RF, Segal JB, Kim MT, Wang Y. Effect of childhood obesity prevention programs on blood pressure: a systematic review and meta-analysis. Circulation. 2014; 129: 1832-9.

10. Campbell MK, Piaggio G, Elbourne DR, Altman DG. Consort 2010 statement: extension to cluster randomised trials. BMJ. 2012; 345: e5661.

11. Angelopoulos PD, Milionis HJ, Grammatikaki E, Moschonis G, Manios Y. Changes in BMI and blood pressure after a school based intervention: the children study. Eur J Public Health. 2009; 19: 319-25.

12. Cameron N. The measurement of human growth. Austrália, Croom-Helm. 1984.

13. Sociedade Brasileira de Cardiologia. Sociedade Brasileira de Hipertensão. Sociedade Brasileira de Nefrologia. VI Diretrizes Brasileiras de Hipertensão. Arq Bras Cardiol. 2010; 95: 1-51.

14. Sociedade Brasileira de Cardiologia. Sociedade Brasileira de Hipertensão. Sociedade Brasileira de Nefrologia. V Diretrizes Brasileiras de Hipertensão Arterial. Arq Bras Cardiol. 2007; 89: e24-e79.

15. Molina MCB, Lopéz PM, Faria CP, Cade NV, Zandonade E. Preditores socioeconômicos da qualidade da alimentação de crianças. Rev Saúde Pública. 2010; 44: 785-92.
16. Fernandes CDR, Batista MS, Pereira TSS, Neto FA, Carletti L, Molina MCB. Validação do questionário de avaliação da atividade física em crianças. Rev Bras Pesq Saúde. 2015; 17: $67-75$.

17. American Academy of Pediatrics. Children, Adolescents, and Television. Pediatrics. 2001; 107: 423-6.

18. WHO (World Health Organization). Global Recommendations on Physical Activity for Health. Geneva; 2010 .

19. ABEP (Associação Brasileira de Empresas de Pesquisa). Critério de Classificação Econômica Brasil 2012. [cited 2018 April 2]. Available from: http://www.abep.org/ criterio-brasil.

20. Brasil. Ministério do Desenvolvimento Social e Combate à Fome. Marco de referência de educação alimentar e nutricional para as políticas públicas. - Brasília, DF: MDS; Secretaria Nacional de Segurança Alimentar e Nutricional; 2012

21. Staiano AE, Beyl RA, Guan W, Hendrick CA, Hsia DS, Newton RL Jr. Home-based exergaming among children with overweight and obesity: a randomized controlled trial. Pediatr Obes. 2018; 13, 724-33.

22. Cunha DB, Souza BSN, Pereira RA, Sichieri R. Effectiveness of a randomized school-based intervention involving families and teachers to prevent excessive weight gain among adolescents in Brazil. PLoS One. 2013; 8: e57498.

23. Brasil. Ministério da Saúde. Ministério do planejamento, desenvolvimento e gestão. Instituto Brasileiro de Geografia e Estatística (IBGE). Pesquisa Nacional de Saúde do Escolar: 2015, Brasil. Rio de Janeiro; 2016.

24. Coelho LF, Siqueira JH, Molina MCB. The nutritional status, physical activity and screen time in students from 710 years: an intervention study in Vitória-ES, Brazil. Demetra (Rio J.). 2016; 11: 1063-83.

25. Meneguci J, Santos DAT, Silva RB, Santos RG, Sasaki JE, Tribess S, Damião R, Júnior JSV. Comportamento sedentário: conceito, implicações fisiológicas e os procedimentos de avaliação. Motricidade. 2015; 11: 160-74.

26. Sorof JM, Lai D, Turner J, Poffenbarger T, Portman RJ. Overweight, Ethnicity, and the Prevalence of Hypertension in School-Aged Children. Pediatrics. 2004; 113: 475-82.

27. Momm N, Hofelmann DA. Qualidade da dieta e fatores associados em crianças matriculadas em uma escola municipal de Itajaí, Santa Catarina. Cad Saúde Colet. 2014; 22: 32-9.

28. Scaglioni S, Salvioni M, Galimberti C. Influence of parental attitudes in the development of children eating behaviour. Br J Nutr. 2008; 99: S22-25.

29. Oosterhoff M, Joore M, Ferreira I. The effects of schoolbased lifestyle interventions on body mass index and blood pressure: a multivariate multilevel meta-analysis of randomized controlled trials. Obes Rev. 2016; 17:1131-53.

Received on September 19, 2019

Final version presented on July 6, 2020

Approved on September 30, 2020 